\title{
Sağlık Alanında Karma Gerçeklik
}

\author{
Dilara Doğan ${ }^{*}$, Tolga Erol ${ }^{2}$, Arif Furkan Mendi $^{3}$ \\ 1* HAVELSAN, Ankara, Türkiye (ORCID: 0000-0001-6139-5200), ddogan@havelsan.com.tr \\ ${ }^{2}$ HAVELSAN, Ankara, Türkiye (ORCID: 0000-0002-3015-0910), terol@havelsan.com.tr \\ ${ }^{3}$ HAVELSAN, Ankara, Türkiye (ORCID: 0000-0002-0750-4012), afmendi@havelsan.com.tr
}

(International Symposium on Multidisciplinary Studies and Innovative Technologies (ISMSIT) 2021 - 21-23 October 2021)

(DOI: 10.31590 /ejosat.1009810)

ATIF/REFERENCE: Doğan, D., Erol, T. \& Mendi, A. F. (2021). Sağlık Alanında Karma Gerçeklik. Avrupa Bilim ve Teknoloji Dergisi, (29), 11-18.

$\ddot{O} \mathbf{z}$

Düşündüğümüz tasarımları, nesneleri, sistemleri hayal hızından sadece biraz yavaş olacak şekilde gerçek dünyamız ile etkileşimli olarak gözlerimizin önüne serilmesini sağlayan karma gerçeklik teknolojisi, gerçek ve sanal nesnelerin bir arada bulunduğu ve gerçek zamanlı olarak etkileşime girdiği, yeni ortamlar ve görselleştirmeler üretmek için gerçek ve sanal dünyaları buluşturan bir gerçeklik türüdür. Eğitimden sağlığa, oyundan pazarlamaya kadar pek çok alanda uygulama örnekleri yaygınlaşan bu teknoloji; gelişen donanım ve internet alt yapılarıyla daha farklı bir boyuta taşınacaktır. Teknolojinin temelinde hayal etme, keşfetme, daha iyi gözleme, öğrenme ve uygulama faaliyetlerini en iyi şekilde deneyimlenmesini sağlamak yatmaktadır. Bu sebeple uygulamalı eğitimin gerekli olduğu, örneğin sağlık ve tıp alanındaki eğitim süreçlerinin daha kaliteli hale getirilmesine yardımcı olması bakımından karma gerçeklik önemli bir yere sahiptir. Teşhis tedavi süreçlerinin daha doğru, hızlı ve etkili bir şekilde gerçekleştirilmesini sağlamaktadır. Gün geçtikçe daha da gelişen dijital ikiz, yapay zekâ ve diğer karma gerçeklik altyapısını oluşturan teknolojilerinin gelişmesiyle birlikte karma gerçeklik teknolojisinin de daha hızlı bir ivmeyle daha çok alanda yaygınlaşması beklenmektedir. Yapılan bu çalışmada teknolojinin avantaj ve dezavantajları değerlendirilecek, ardından teknolojinin sağlık alanındaki uygulamaları ve gelecek öngörüleri ele alınacaktır.

Anahtar Kelimeler: Karma Gerçeklik, Sağlık Uygulamaları, Artırılmış Gerçeklik.

\section{Mixed Reality Technology in Healthcare}

\begin{abstract}
Mixed reality technology, which enables the designs, objects, systems we think of to be revealed interactively with our real world at only a little slower than the speed of imagination, real and virtual worlds to produce new environments and visualizations where real and virtual objects coexist and interact in real time. It is a kind of reality that brings together. This technology, which has become widespread in many fields from education to health, from games to marketing, will move to a different dimension with developing hardware and internet infrastructure. The basis of technology is to enable the best way to experience the activities of imagination, discovery, better observation, learning and application. Therefore, mixed reality has an important place in terms of helping to improve the quality of education processes in the field of health and medicine, where applied education is necessary. It also enables diagnosis and treatment processes to be performed more accurately, quickly and effectively. In this study, after discussing the studies in the field of health in the literature, the requirements of technology were examined. After evaluating the advantages and disadvantages of technology, the applications of technology in the field of health and our future predictions are mentioned. It is expected that the technology will become widespread in more areas with a faster acceleration with the development of the technologies that make up the developing digital twin, artificial intelligence and other mixed reality infrastructure.
\end{abstract}

Keywords: Mixed Reality, Healthcare Applications, Augmented Reality.

\footnotetext{
* Sorumlu Yazar: HAVELSAN, Simülasyon Otonom ve Platform Yönetim Teknolojileri, Ankara, Türkiye, ORCID: 0000-0001-6139-5200, ddogan@havelsan.com.tr
} 


\section{Giriş}

Ünlü düşünür Konfüçyüs'ün 'Duyduğumu unuturum, gördüğümü hatırlarım, yaptığımı anlarım' sözünde ifade ettiği gibi bir şeyi öğrenmenin en iyi yolu onu uygulamak yoluyla öğrenilmesidir. Çoğu eğitim süreçlerinde de bu ilke esas alınarak pratik ve uygulamaların olabildiğince arttırılabilmesi önemsenmektedir. Eğitim programları da buna uyumlu olacak şekilde hazırlanmaktadır. Uygulama imkânı olmayan veya kısıtlı olan durumlarda ise görsel materyal kullanımına, görüntüleme ve görselleştirmeyle ilgili teknolojilere önem verilmiştir. Bilim de birçok alanda görülmeyeni ve bilinmeyeni keşfetmek, anlamak ve anlamlandırmak amacıyla çizimler, resimler ve modeller kullanılmaktadır. Kullanılan bu materyaller ile ilgili kavram ve teknolojinin daha iyi anlaşılması mümkün olabilmektedir. Yeni nesil teknolojilerden olan artırılmış, sanal ve karma gerçeklik teknolojileri görselleştirme, hayal etme ve uygulama ihtiyaçlarını karşılamak amacıyla ortaya çıkmıştır. Sanal gerçeklikle gerçek dünyadan bağımsız olarak yeni gerçeklikte bir dünya tasarlanmakla birlikte, artırılmış gerçeklik ise gerçek dünya üzerinden işlemler yapmayı sağlarken, karma gerçeklikte ise artırılmış gerçekliğin bir adım önüne çıkarak sanal nesnelerin gerçek dünyaya hem konumlandırılması hem de sürekli etkileşim halinde olmaktadır. Karma Gerçeklik (Mixed Reality) terimi ilk defa, 1994 yılında Paul Milgram ve Fumio Kishino'nun kaleme aldığı "Karma Gerçeklik Görselleştirmelerinin Sınıflandırılması" (A Taxonomy Of Mixed Reality Visual Displays) makalesinde bahsedilmiştir (HoloNext, 2020). Çalışmada bahsedilen bu teknoloji Microsoft tarafindan bir ürün haline getirilerek 2016 yılında dünyaya sunuldu. Sonrasında ise hızla geliştirilip, eğitimden sağlığa kadar pek çok sektöre yönelik uygulama ve ürünler geliştirilerek geliştirilmeye devam edildi.

Karma gerçeklik, arttırılmış ve sanal gerçeklik iş birliği potansiyeli sunmaktadır. $\mathrm{Bu}$ alanlar birbirleriyle nesnelerin internetinin sunduğu imkânlarla kesişebilmektedir. Bu karşılıklı dönüşüm dijital ikizler, blockchain ve yapay zekâ gibi pek çok teknolojinin de yeni kullanım alanlarına sahip olmasına neden olmaktadır. Dijital nesnelerin sanal nesnelerle daha da gelişmiş ve ayırt edilemeyen bir şekilde bir arada bulunması kullanıcılara farklı deneyimleri bir arada yaşayabileceği yeni bir dünyanın oluşmasına da yardımcı olacaktır. Gerçekliği arttıracak veriler her yerde mevcuttur, her şeyden ilgili veriler elde edilebilir. Eğitim, sağlık, iş dünyası, askeri, karar verme süreçleri gibi birçok alanda karma gerçeklik kullanılabilmektedir.

Özellikle sağlık ve tıp eğitimlerinde kullanılacak uygulamaların eğitim kalitesinin arttırılmasına önemli ölçüde katkı sağlamaktadır. Tıpta sadece eğitim alanında değil, aynı zamanda teşhis ve tedavi süreçlerinde de hem sağlık personeline hem de hastalara yardımcı olması beklenmektedir. Bunun yanı sıra dijital ikiz teknolojilerindeki gelişmeler sonucunda da dokuların, organların hatta insanların dijital ikizlerinin yapılması sonucunda, bu ikizler karma gerçeklik teknolojisiyle entegre olarak kullanılabilecektir. Böylece hastaların dijital kopyalarının karma gerçeklik ile detaylı olarak görselleştirilmesi çeşitli durumlarda teşhis ve tedavi süreçlerini hızlandıracaktır. Hatta yapay zekâ sistemleriyle teşhis konulabilmesi mümkün olacaktır.

Yaptığımız bu çalışmada öncelikle karma gerçeklik teknolojisine doğru ilerlerken karşılaştığımız temel kavramlardan bahsettik. Ardından teknolojinin literatürdeki kullanımı ve yapılan çalışmaları irdeledik. Teknolojinin avantaj ve dezavantajları inceledikten sonra, teknolojinin kullanımı için gereksinimleri ele aldık. Ardından sağlık alanında karma gerçeklik uygulamalarını ve mevcut çalışmalar sonucunda elde edilen bilgi birikimi sonucunda gelecek öngörülerimize yer verdik.

\section{Temel Kavramlar}

\subsection{Sanal Gerçeklik}

Sanal gerçeklik (SG), kullanıcılara tamamen sanal olarak oluşturulmuş bir dünya deneyimini o dünyada olduğu deneyiminin yaşatıldığı bilgisayar tabanlı ortamla sağlanmasıdır. Kullanıcılar, çeşitli donanımlarla (kontroller, kast veya gözlük) oluşturulan bu sanal dünyaya dâhil olarak çeşitli aksiyonlar gerçekleştirebilmektedir. İlgili sanal ortama girdikten sonra bir manada gerçek dünya ile iletişimini keserek sanal dünya deneyimini yaşamaktadır. Başa takılan ekran veya başlık kullanarak konsol veya bilgisayara bağlıyken dokunmatik kontroller yardımıyla nesneleri hareket ettirilebilme veya yönlendirmeyle bilgisayarla oluşturulmuş görüntü ve ses dünyasını deneyimleme firsatı sunulmaktadır.

\subsection{Artırılmış Gerçeklik}

Artırılmış gerçeklik (AG), gerçek dünyadaki ortam ve içindekilerin, sanal ortamda üretilen; ses, görüntü, grafik ve GPS verileriyle zenginleştirilerek meydana getirilen canlı görünüm olarak ifade edilebilir. Artırılmış gerçeklikte, kullanıcılar sanal içerikler eklenirken gerçek dünyayı görürler ve etkileşime girerler. Basitçe gerçekliğin bilgisayar tarafından değiştirilmesi ve artırılması anlamına gelmek birlikte esasında gerçek dünya nesnelerinin üzerine sanal veriler yerleştirmesine dayanmaktadır. Pokémon GO, teknolojinin en iyi bilinen örnekler uygulamalarından biri olup teknolojinin herkesçe tanınır hale gelmesinde etkisi büyüktür.

\subsection{Karma Gerçeklik}

Karma gerçeklik (KG), artırılmış ve sanal gerçeklik teknolojilerinden sonra çıkarak, geliştirilmiş bir artırılmış gerçeklik deneyimi olarak ifade edilebilmektedir. Karma gerçekliğin artırılmış gerçeklikten farkı sanal nesnelerin gerçek ortamlarda gerçek nesneler gibi konumlandırılmasıdır. $\mathrm{Bu}$ konumlanma gerçek zamanla ve gerçek nesnelerle hizalanarak gerçekleştirilmektedir yani sanal nesneler sadece gerçek dünya üzerine bindirilmez, aynı zamanda onunla sürekli olarak etkileşime girebilmektedir. Karma gerçeklikte sanal ve gerçek veriler aynı ortamda birleştirilmesiyle sanal verinin gerçekliğinin artırılması sağlanırken var olan gerçek ortamında sanal verinin kullanılabileceği ortamlara dönüştürülmesi sağlanmaktadır (Park et al., 2012). Bu dönüşümler, gerçekliğin algılanış biçimini de şekillendirmektedir.

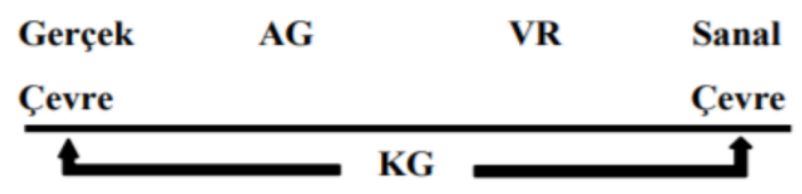

Görsel 1: Artırılmış, Sanal ve Karma Gerçeklik Teknoloji Ilişkileri

Artırılmış, sanal ve karma gerçeklik için önemli olan terimler ve açıklamalar Tablo 1'de görülmektedir. 
Tablo 1. Artırllmış, Sanal ve Karma Gerçeklik için Önemli Olan Terimler ve Açıklamaları (Intel, 2020)

\begin{tabular}{|l|l|}
\hline Terim & Açıklama \\
\hline $\begin{array}{l}\text { Saniye başına } \\
\text { düşen kare } \\
\text { sayısı (FPS) }\end{array}$ & $\begin{array}{l}\text { Sistemin birbiri ardına görüntüleri veya kareleri } \\
\text { yayınlayabileceği frekans değeridir. Iyi bir kullanıcı } \\
\text { deneyimi oluşturmak ve görüntü akı̧ının düzgün } \\
\text { olabilmesi için 60 FPS'den fazla olmalıdır kare hızı. }\end{array}$ \\
\hline Görüș alanı & $\begin{array}{l}\text { Görülebilen dünyanın gözlemlenebileceği açının tarandığ1 } \\
\text { alandır. Görüş alanının gerçeğe göre dar olması doğru ve } \\
\text { rahat bir kullanıcı deneyimi sağlamayacaktı. }\end{array}$ \\
\hline $\begin{array}{l}\text { Serbestlik } \\
\text { Derecesi (DoF) }\end{array}$ & $\begin{array}{l}\text { Bir nesnenin hareket edebileceği veya dönebileceği yön } \\
\text { sayısıdır. Gerçek dünyada çok boyutlu bir şekilde nesneler } \\
\text { hareket etmektedir. X,y ve z eksenlerinin yanı sıra dikey, } \\
\text { yatay ve boylamsal dönme eksenlerde göz önüne } \\
\text { alınmaktadır. Ne kadar fazla serbestlik derecesi varsa o } \\
\text { kadar geçekçi bir kullanıcı deneyimi sağlanır. }\end{array}$ \\
\hline Gecikme süresi & $\begin{array}{l}\text { Mevcut sistemin komutlara cevap verirken geçen } \\
\text { zamandır. Gerçeklik deneyiminin kaliteli bir şekilde } \\
\text { sağlanması için gecikme süresinin minimum düzeyde } \\
\text { tutulması önemlidir. }\end{array}$ \\
\hline
\end{tabular}

\section{Literatür Özeti}

Eğitim teknolojiler düşünüldüğünde artırılmış, sanal ve karma gerçeklik teknolojileri öncelikli olarak karşımıza çıkmaktadır. Özellikle tıp gibi eğitim süreçlerinin maksimum verimlilikte verilmesi kritik öneme sahip olan alanlarda görüntüleme teknolojileri aktif olarak kullanılmaktadır. Google Glass ile daha ön plana çıkan karma gerçeklik teknolojisi tıp eğitimindeki uygulamaların etkili bir şekilde gerçekleştirilmesi için geliştirilmiştir. Mobiliteye sahip saydam cama sahip gözlüklerle nerdeyse normal gözlüklerden ayrılamayacak kadar iyileştirilmiş donanımlarla artırılmış gerçeklik ekranlarını gözlerimizin önünde taşıyabilmekteyiz. Bunun yanı sıra kullanıcının gözünü çevirdiği yöne odaklanarak buna uyumlu hareket eden akıllı kamera sistemi ile bir eğitmen tarafindan kullanılması durumunda uygulamalı derslerin detaylı bir şekilde kayıt altına alındıktan sonra izlenmesi mümkün olabilmektedir. Başlangıçta teknoloji normal bir gözlüğe küçük ebatlarda Android bir cihazın eklenmesiyle göz önüne tek taraftan gelen sanal bir yansılarla bildirim ve görüntüleri iletirken, Microsoft'un Hololens ile yapmış olduğu önemli bir atılım olan karma gerçeklik teknolojisiyle birlikte kadavra diseksiyonlu anatomi eğitimlerinin yenilikçi bir yaklaşımla dijital simülasyonlar yardımıyla yapılabileceğinin önemli bir örneği olmuştur. Cleveland Klinik ve Case Western Reverse Üniversitesi tarafından tıp eğitiminde kullanılan karma gerçeklik teknolojisiyle oluşturulmuş olan Hololens, alışılmışın dişında insan anatomisini 3B hologramlar kullanarak görselleştirerek uygulamalı eğitim için farklı bir deneyim sunmaktadır. Hologramlar sayesinde tek bir kesitte bulunan farklı doku ve sistemlerin ayrı olarak da incelenerek dokunsal geri bildirimde de bulunulabilmektedir.

Başlangıçta kullanılan sanal gerçeklik gözlükleri yüksek performans ve işlem gücünden dolayı kablolu olarak tasarlanmıştır. Kablolu gözlüklerin kullanımı ise pratik olmamakla birlikte aynı zamanda karmaşa oluşturmaktaydı. Hem görsel olarak hem de kullanım olarak portatif gözlüklerin, önce 2013 y1lında Google Glass devamında 2016 y1lında Hololens'in Microsoft tarafından piyasaya çıkarılmasıyla birlikte yeni bir yaklaşım ortaya konulmuştur. Bu yaklaşımda her gözlüğün kendi işlemcisi kendi içinde yer alacak şekilde bir mimari oluşturulmuştur. Cerrahi müdahalelerin robotlar tarafindan yapılabilmesiyle küçük kesi yöntemlerinin yaygınlaşmasıyla önü açılarak gelişen klasik açık cerrahi yöntemlerinin yerini küçük kesi yöntemleri almaya başlamıştır. Teknolojinin gelişimiyle bu tekniğin yaygınlaşmasının yanı sıra operasyonlara olan güven de artmaktadır. Son yillarda kullanıma sunulan Microsoft Hololens2, Philips ve Microsoft'tan yeni nesil cerrahi yöntemlerde kullanılmak amacıyla önemli bir proje niteliği taşımaktadır. Küçük kesiler yoluyla cerrahide kullanılan kateter gibi özel aletlerin keşiden içeriye ilerletilerek X-ray, ultrason veya mikro kameralar gibi görüntüleme teknik ve teknolojilerinin yanı sıra navigasyon teknolojilerini kullanarak kalp, beyin, karaciğer vb. diğer organları tedavi süreçlerinde kullanılmaktadır. Gerek hastalıkların teşhis süreçleri için gerekse tedavi süreçleri için bu görüntüleme teknolojileri kullanılmaktadır (Groves, 2019).

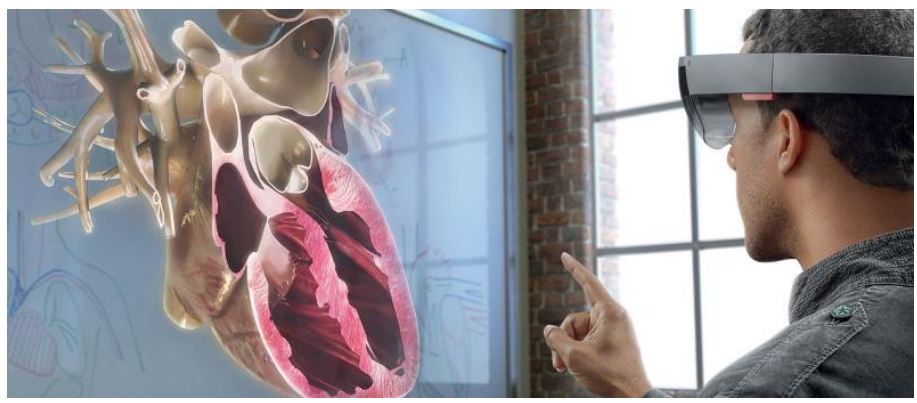

Görsel 2: Cleveland Klinik ve Case Western Reverse Üniversitesi Hololens Kullanımı (Case Western Reverse University, 2016)

Görüntüleme metotları genellikle yüzey oluşturma ve hacim oluşturma olmak üzere iki temel prensibe dayanmaktadır. Kökeni daha eskilere dayanan yüzey oluşturma prensibinde çözünürlük kapasitesi aynı anda sadece tek bir doku tipini fark edebilmekle birlikte yüzey oluşturan $2 \mathrm{~B}$ yöntemler doku ve organlar arasındaki ilişkilerin incelenmesi konusunda yeterli olmaması ve düzlem üzerinde izlemede kısıtlı kalmasıyla birlikte 3B yöntemlere yani hacim oluşturmaya yönelik prensibin geliştirilmesi yönünde bir motivasyon ortaya çıkmıştır. Bunun yanı sıra farklı yoğunluk değerlerine sahip organların dış hatlarının birbirlerinden ayrılması kolay iken yakın yoğunluğa sahip olanlarda farkın ayırt edilmesi oldukça zordur. 3B yöntemi yani hacim oluşturma yöntemiyle farklı yoğunluklara sahip farklı dokuların yoğunluklarına göre farklı renklerle renklendirilmesi durumu söz konusudur. Dünya genelinde yapılan yıllık 600 milyon tıbbi görüntülemenin yarısında 3B teknik kullanılmaktadır. Fakat elde edilen bu sonuçların 2B da izleniyor olması bu alanda istenilen seviyede bir görselleştiril olup olmamasını akıllara getirirken böyle bir ihtiyacın olduğuna da vurgu yapmaktadır. Uygulanan tekniklerin izlenmesi amacıyla 3B da görüntü elde etmek amaciyla "Echopixel" görüntüleme uygulaması tasarlanmıştır. Tıp alanında karma gerçeklik teknolojisini ele alan uygulama BT, MRG, PET ve ultrasondan elde edilen verilerin 2B monitörden $3 \mathrm{~B}$ ortama aktararak ilgili doku ve organların incelenmesini sağlamaktadır. Cihazın monitörü, kullanıcının baş hareketlerine göre görüntü alan dört farklı kameraya sahipken, damar uzunluklarının ölçümünü hedef alan bir çalışmada Echopixel'in kullanım avantajları, 3B ekran ve dokunsal geribildirim sayesinde yöntemin geliştirilmiş tekrarlanabilirlik ve yüksek doğruluk oranıyla ölçüm sağladığını ortaya koyulmuştur. Yapılan diğer bir çalışmaya göre siroz hastalığına sahip hastaların damarlarındaki değişimlerin takip 
edilmesi ve gerekli durumlarda yapılacak olan katetarizayon işlemi doku ve organlara daha iyi hâkim olunarak daha iyi bir manevra kabiliyeti sunmaktadır. Görüntüleme teknolojileri sağlık alanında kullanımının oldukça önemli ve vazgeçilemez bir yere sahip olduğu yapılan çalışmalarla görülmektedir.

\section{Teknik Gereksinimler}

Artırılmış, sanal ve karma gerçeklik teknolojilerinin gerçekleştirilebilmesi sadece bilgisayar üzerinde alışılıp test edilmesi şeklinde olmayıp gözlük kullanımına da ihtiyaç duyulmaktadır. Geçmişte normal bir gözlüğe, ayrı bir modülden masa üstü bilgisayar, dizüstü bilgisayar ya da mobil telefon kameraları açıldıktan sonra aktive olan programın holografik modeller eklemesi ile oluşurken, artık giyilebilir görüş sistemleri ya da sanal gösterge panelleri yöntemiyle gerçekleştirilmektedir. Kullanımı giderek artan giyilebilir görüş sistemlerinin video, optik ve görüş alanına yansıtanlar olmak üzere 3 farklı çeşidi bulunmaktadır. Optik arayüzlü giyilebilir görüş sistemlerine örnek olarak Google Glass, Microsoft Hololens ve Magic Leap gözlükler verilebilir. Bu tip gözlüklerin çalışma prensipleri genel olarak aynı olmakla birlikte ağırlıkları, büyüklükleri, tasarımları, elektromanyetik, hareket takip sistemleri farklıdır. Genel çalışma prensibi olarak şeffaf olan gözlük camlarıyla dış dünyayı görebilirken, görüş alanına veya hedef objenin üzerine ilgili sanal görüntü eklenmektedir. Gözlükler sesli komutlarla, el hareketleriyle veya kontrol edici diğer donanımlar kullanılarak arayüz üzerinden menü değiştirme, programlarla ilgili tercihleri yapilarak kontrol edilebilmektedir.

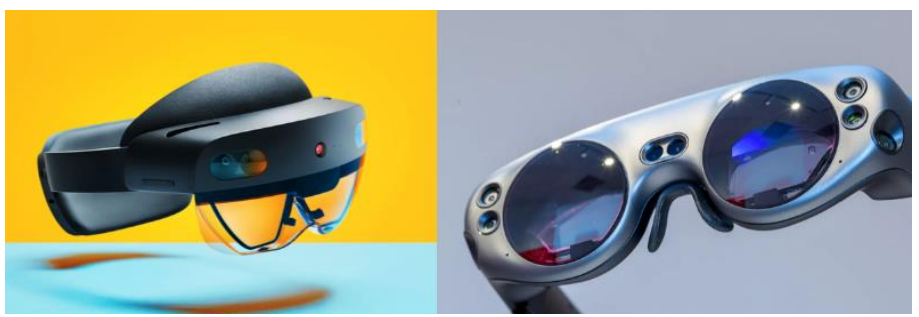

Görsel 3: Hololens 2 ve Magic Leap One (Steiger, 2020)

Karma gerçeklik, donanım gereksinimleri diğer birçok teknolojiye oranla daha yüksek seviyede olsa a kullanım alanı oldukça geniş bir teknolojiye sahiptir. Yüksek CPU, GPU ve bellek gerektirmekle birlikte bileşenlerin birbirleriyle senkronize çalışacak yüksek performansa sahip olması gerekmektedir. Henüz herhangi bir donanım kullanmadan karma gerçeklik teknolojisini kullanmak mümkün olmasa da karma gerçeklik kavramını gerçek dünyaya taşıyan karma gerçeklik gözlükleri piyasaya çıkmış olup tüm dünyanın gözlerini üstüne çekmiştir. Karma gerçeklik gözlüklerinin çalışma prensibi ve kullanılan donanımları şöyledir: Takılan saydam ya da yarı saydam gözlükler sayesinde mekânda holografik görüntülerin görüntülenmesini sağlar. Etkileşimlere izin vermek için bakış, ses ve jestleri bütünleştirir. Böylelikle 3D görüntünün ne alanda nasıl kullanılması gerektiği kişinin donanım ve hayal gücüne kalarak her alanda kullanılmasına olanak tanır. Gözlüklerin temel donanım birimleri aşağıdaki gibi özetlenebilmektedir.

- Holografik İşlem Birimi (HPU- gerçek ve hologram verilerini birleştiren bir işlem birimi)

- Üst düzey CPU (bilgisayar işlem birimi) ve GPU (grafik işlem birimi)
- Ataletsel ölçüm birimi (IMU - bir vücudun özgül kuvvetini, açısal hızını ve vücudun yönünü ölçen ve raporlayan elektronik bir cihaz) IMU; ivmeölçer, jiroskop ve manyetometre içerir.

- Gelişmiş sensörler (baş izleme, göz izleme, kamera)

- Mikrofon

- Video Kamera

\section{Teknolojinin Avantaj ve Dezavantajları}

\subsection{Teknolojinin Avantajları}

Karma gerçeklik teknolojisinin sunmuş olduğu avantajları aşağıda verilmektedir.

- Sağlık personelinin hızlı teşhis, tedavi ve acil müdahalede bulunmasını sağlayacak bir performansa sahip olan teknoloji uzaktan bu süreçlerin sağlıklı bir şekilde sürdürülmesine veya sanal hasta konsültasyonlarının gerçekleştirilmesine olanak sağlamaktadır.

- Kişiselleştirilmiş tıpta klinik teşhislerin konulması ve bu teşhislere uygun kişiselleştirilmiş tedavi uygulama planlarının gerçekleştirilmesi süreçlerinin iyileştirilmesine yardımcı olmaktadır.

- MRI ve BT taramaları gibi tetkikleri, ameliyattan önce ve ameliyat sirasında uzmanlara ve cerrahlara yardımcı olmak ve böylece hassasiyeti artırmak ve ek müdahale ihtiyacını azaltmak için kullanılmaktadır.

- Eğitime ve tıp dünyasına yeni bir yaklaşım getiren, eğitim etkinliği ile öğretmen ile öğrenci üzerinde, ameliyathane ve muayenehanede doktorlar üzerinde MR kullanılmasının birçok avantajı bulunmaktadır.

- Prosedürler sanal olarak vücuda hiçbir zarar vermeden birçok kez tekrarlanabilir.

- Sanal bedenin ölmesi gerekmez-gerçekçi görselleştirmeler için birçok işlev simüle edilebilir.

- Organlar şeffaf ve hareket halinde modellenebilir.

- Korkulan durumların, cerrahi operasyonların eğitim ve MR simülasyonlarında sınırsız tekrarını yapabilmek ve deneyimi artırmak mümkündür.

- Hastaların kendi durumlarını, tedavilerini, ameliyatlarını ve iyileşmelerini öngörmelerine yardımcı olunabilir.

- Acil durumlarda halk için sağlık hizmeti sağlayıcılarının ve hayat kurtaran ekipmanların (defibrilatör gibi) konumları haritalandırılabilir.

- Gerçek 3D Ultrason deneyimi sağlanabilmektedir.

3D Görselleştirme tıpta birçok alanda yararlıdır. Bunlar:

- Anatomik yapıların görselleştirilmesi

- Bireysel hasta anatomisi

- Resimli ameliyat prosedürleri

- Radyasyon terapisini planlamak

- Bireysel anatomik modellerin görselleştirilmesi 


\subsection{Teknolojinin Dezavantajları}

Artırılmış ve karma gerçeklik teknolojinin kullanımında tercih edilen donanımların gerçek görüş alanı ve mekânlarla ilişkilendirilip gösterilmesi sonucunda bu teknolojileri kullanırken gerçek dünyadan kopma, bağımlılık yapma gibi mental ve ruhsal; baş dönmesi, mide bulantısı gibi fiziksel semptomlara sebep olmazken sanal gerçeklik gözlüklerinin kullanımında bu semptomlar görülmektedir (HASPULAT, 2021). Bunun yanı sıra teknolojinin bazı dezavantajlı görülebilecek noktaları aşağıda özetlenmiştir.

- Ekranların göz sağlığına genel olarak zarar verdiği bilinmektedir. Karma gerçeklik gözlüklerinin göz sağlı̆̆ını bozacağını düşünmekteyiz fakat bu konu ile ilgili henüz net bir bilgi bulunmamaktadır.

- Karma gerçeklik uygulamalarının maliyetleri henüz istenen seviyelerde değildir. Teknolojinin aktif kullanımı için ihtiyaç duyulan donanım alt yapısının yüksek seviyede olması maliyetli olmaktadir.

- İhtiyaç duyulan altyapı ve donanım ihtiyaçlarıyla birlikte yetkin personel bulunması konusunda tedarik sıkıntıları meydana gelebilmektedir.

- Artırılmış ve karma gerçeklik uygulamaları için içerik üretmek, gerekli alt yapıları sağlayacak yeterlilikte uygulamaların geliştirilmesi için yüksek bilgi ihtiyacı, ortamlar arasındaki veri taşıma alt yapı eksikliği, geliştirme ve bakım masrafları göz önüne alındığında zorlayıcı ve masraflı bir süreç gerektirebilmektedir.

Artırılmış gerçeklik uygulamalarının önündeki dezavantajların teknolojinin ilerlemesi ve zaman içinde olumlu sonuçların alınması ile birlikte yönetilebilir hale getirilmesi ya da uzun vadede ortadan kaldırılması değerlendirilmektedir.

\section{Karma Gerçekliğin Sağlık Alanında Kullanımı}

Sağlık, birçok konuda hata kabul etmeyen, yapılan hatalar sonucunda ağır bedellerin ödenebildiği, eğitim ve uygulamalarının çok dikkatli bir şekilde yürütülmesi gereken bir alandır. $\mathrm{Bu}$ sebeple sağlık alanında geliştirilen teknolojilerde hataların önlenmesine ve daha iyi bir eğitim imkânı sunmaya yönelik olacak şekilde bir gelişim sergilemiştir. Ultrason, MR, EKG gibi cihazlar özellikte tıpta tanı koyma ve tedavi süreçlerinde oldukça önemli bir yere sahip görüntüleme teknolojileriyle üretilmiştir. $\mathrm{Bu}$ teknolojilere ek olarak sağlık biliminde her gün yeni teknikler, yeni teknolojiler çıkmaya devam etmektedir. Bu gelişmelerle birlikte AG, SG ve KG teknolojileri de sağlık alanında kullanımlarına yönelik uygulamalar yaygınlaşmaya başlamıştır.

Karma gerçekliği kullanmaya uygun en önemli alanlardan biri de eğitimdir. Eğitimde kullanılması olası alanlar incelendiğinde ise uygulama ağırlıklı alanlarda daha faydalı ve maliyet etkin çözümler sunmaktadır. İlgili uygulama ortamı fiziksel olarak nelere sahipse sanal olarak da aynı olacak şekilde modellenebilmektedir. Sanal nesneler ne kadar gerçeğe yakın olursa eğitimin kalitesi o kadar gerçek uygulamalı eğitime yakın olacaktır. Karma gerçeklik sadece eğitimle sınırlı kalamayarak üretim, tasarım, geliştirme, raporlama, analiz, kalite kontrol, dağıtım gibi alanlarda da önemli hale gelmeye başlamaktadır.
Özellikle tıp gibi uygulamanın önemli olduğu alanların eğitimlerinde karma gerçeklik teknolojisinin kullanımı önem arz etmektedir. Visual3d Medical, HoloForge Interactive karma gerçeklik ile tele-tıp alanlarında holografik tıbbi ve cerrahi çözümler sunmaktadır. HoloLab artırılmış, sanal ve karma gerçeklik kullanarak gerçek ve sanal dünyaların birbirlerine bağlanmasını sağlarken, apoQlar yapay zekâ kullanılarak karma gerçeklik temel alan tıbbi uygulamalar geliştirmektedir. Medivis de benzer şekilde artırılmış gerçeklik ve yapay zekâ kullanarak daha spesifik olarak cerrahiye yönelik ileri seviyede görselleştirmeye yönelik çalışmalar yapmaktadır.

Şimdiye kadar tıpta deneysel araştırma ve eğitim temel olarak plastik modellerin diseksiyonuna ve incelemesine dayanıyordu. Bilgisayarlı 3B insan modelleri, tıpta araştırma ve eğitim için yeni bir yaklaşım sağlamıştır. Anatominin tam olarak anlaşılması ya da hastalığın tam olarak nerede nasıl göründüğünün bilinmesi hem hastalığın teşhisinde hız kazandırırken hem de daha anlaşılır görüntüler sayesinde teşhis ve tedavi süreçlerinde iyileştirme sağlanmış olur.

Tıbbi araştırma için kadavra sıkıntısı nedeniyle, tıp eğitiminde sanal kadavra kullanmak büyük kolaylık ve avantaj sağlamaktadır. Tıp eğitiminde, bilgisayardaki bir insan vücudunun gerçekçi bir taklidinin kullanılmasıyla sürdürülen eğitim daha yararlı olacağı görülmektedir. Bunun yanı sıra tıp eğitimi sürecinde kadavra bulma problemi söz konusudur. Ayrıca kadavra eğitimi birçok açıdan gerçekçi olmaması gibi birçok dezavantajlara sahiptir. Örneğin bir stajyer kadavrada kan damarı keserse, kan kaybı vs. gibi olumsuzlukları göremeyeceği için gerçekçiliğin yeterli düzeyde sağlanamaması durumu söz konusudur. Bunun yanı sıra kadavralarda yapılan hiçbir işlem tersine çevrilemez. Sanal gerçeklik ile eğitimde ise bir damar kesilince neler yaşanabileceğini görmek ve işlemi geri almak ve yeniden yeni bir strateji ile sürdürmek mümkündür.

Anatomi eğitimin daha etkili ve verimli hale getirilmesi amacıyla, bir grup tıp ögrencisi tarafından Case Western Reserve Üniversitesinde pilot bir uygulama yapılmıştır. Bu uygulama ile kadavralara, çeşitli kimyasallara ve eğitim esnasında meydana gelebilen alerjik reaksiyonlar olmadan bir anatomi öğrenme modeli üzerinde çalışılmaktadır. Kadavralar tıp eğitimi için çok önemli ancak yaşayan bir insan anatomisini öğrenmek için yeterli değiller. Örnek olarak; ciğerlerin sönmesi, dokuların ve renklerin farklılık göstermesini söyleyebiliriz. Microsoft'un 2016 yılında geliştiriciler ve ticari kullanımlar için piyasaya sunduğu karma gerçeklik gözlükleri ile kullanılabilen HoloAnatomi uygulaması ile öğrencilere gerçek bir insan anatomisi hologramlar ile gösterilebiliyor ve kullanıcılar el hareketleri ve sesli komutlar ile detaylı incelemelerde bulunabiliyorlar. Kadavraların bozulmaması için kullanılan bazı kimyasalların, bazı bünyelerde alerjiye sebep olabilmektedir. Bunun yanı sıra kadavraların korunması ise ayrıca maliyetli bir süreçtir. Örneğin, kadavraların korunması için soğutma ve havalandırma sistemlerinin de yüksek maliyetlere sebeptir. HoloAnatomi ile öğrenmek için harcanan zamandan da tasarruf sağlanıyor. Örneğin, öğrenciler bu uygulama ile tüm dolaşım sistemini görebiliyorlar; böylece tüm vücudu açmak gerekmiyor. Sonbahar döneminde pilot uygulama devam ettirilecek ve öğrencilerin dönem sonunda istenen hedeflere ulaşıp ulaşmadıkları değerlendirilecek. Ayrıca birkaç hafta süresince de öğrencilerin bu anatomi üzerinde kampüs dışında, yani anatomi laboratuvarlarına gerek olmadan, çalışmaları da sağlanmış olacak. Başlangıçta değişime karşı direnç olduğunu ve bunun aslında her yeni gelen teknolojide insanların şüpheye yaklaşmasından kaynaklandığının ancak bir 
kez deneyimleyen kullanıcıların fikirlerinde değişmeler olduğunu da belirtiliyor.

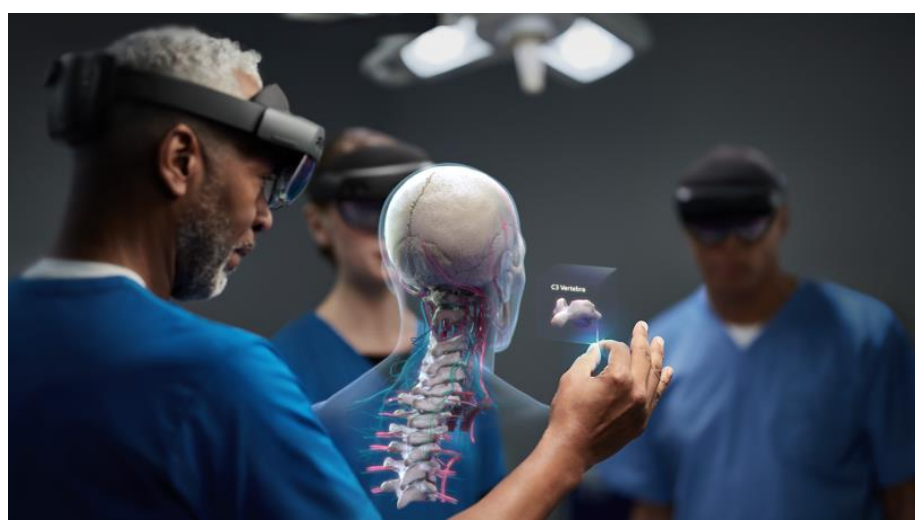

Görsel 4: Hololens Cerrahi Operasyonu (Microsoft, 2021)

Sağlık alanında karma gerçekliğin uygulamasına dair yaşanan bir başka örnek: Microsoft'un iş ortaklığı yaptığı Apoqlar Holomedicine ile karma gerçekliğin pazarlamasını yapmaktadır. VSI Holomedicine ile yapılan görüntüleme sayesinde bir sinir kurtarıldı. Prof.Dr.Mark McGurk olayı "Vakamız klinik olarak çok zorlayıcı olan ve bir yüz sinirini feda etmeyi düşündüğümüz kötü huylu tümörü olan bir kadın hasta. Bu vakada iki yenilikçi teknolojiyle mümkün kılınan görüntülemeyi kullanarak mevcut prosedürü değiştirebildik: bunlardan birincisi, UCL'den Dr. Morley tarafindan parotis bezi boyunca küçük bir yüz sinirini izleme yeteneği, ikinci adımda apoQlar teknolojisi. Görmesi ve anlaması çok kolay olan bu harika görüntüleri elde etmek için VSI Holomedicine kullandık. Bu bizi ameliyatı yeniden planlamaya ve hastanın yüz sinirini kurtarmamıza yardımcı oldu." şeklinde ifade etmiştir (Mcgurk, 2021). Bunun yanı sıra yapılan yapılan birçok cerrahi operasyonda örneğin ortopedi ameliyatlarında da teknoloji aktif olarak kullanılmaktadır (Verhey et al., 2020).

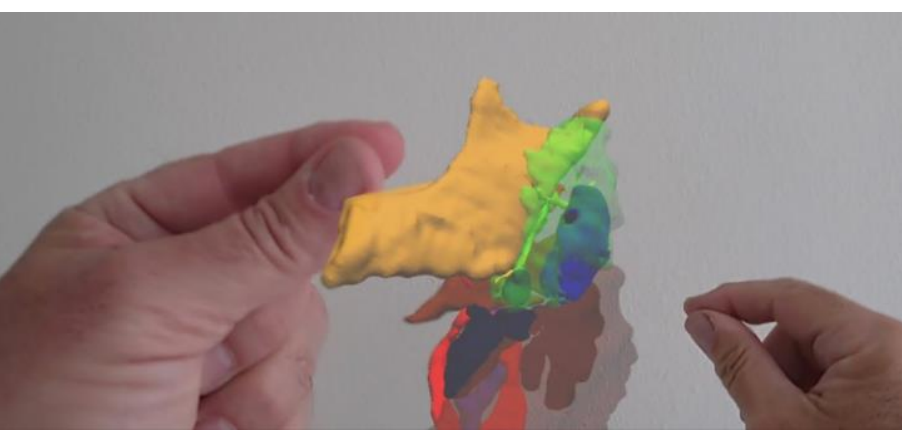

Görsel 5: VSI Holomedicine (apoQlar, 2020)

Microsoft Amerika'nın eski medikal danışmanı Dr. Rafael Grossmann, 2014 yılında Google Glass gözlüğünü Dünya'da ilk kez ameliyatta kullanarak ameliyat esnasında izleyiciler, Dr. Grossmann'ın gözünden ameliyatı bizzat takip etme firsatı elde etmiştir. 2017 yılında İstanbul Üniversitesi bünyesinde Tübitak 1512 (BIGG) çağrısını kazanarak başlatılan arttırılmış gerçeklik teknolojisiyle yapay zekâ destekli medikal pratik eğitimi simulasyonu geliştirilmesi” projesinin devamında, 2018“de Türkiye'deki ilk arttırılmış ve karma gerçeklik laboratuarı olan "İ.Ü. Medikal Hologram Laboratuarı" kurulmuştur. Dr. Grossmann da 2019'da İstanbul Üniversitesi'nde yürütülen "Medikal Hologram Laboratuarı" projesine de stratejik ortak olarak bu alanda yapılan çalışmalara destek vermiş ve bu çalışmaları "Tıbbın Geleceği”" gibi çeşitli uluslararası konuşma ve konferanslarda tanıtmıştır. 2019 y1lı sonlarında İstanbul
Üniversitesi, İngiltere'nin köklü hastanelerinden Barts Hospital bünyesindeki Royal London Hospital ile böbrek anatomisi ve böbrek nakli ameliyatlarının sanal gerçeklik ile simülasyonu projesi konusunda ortak olmuştur. Arttırılmış gerçeklik alt yapılı çalışmaların birçoğunun genellikle anestezi ve anatomi alanlarında üretildiği görülmüştür.

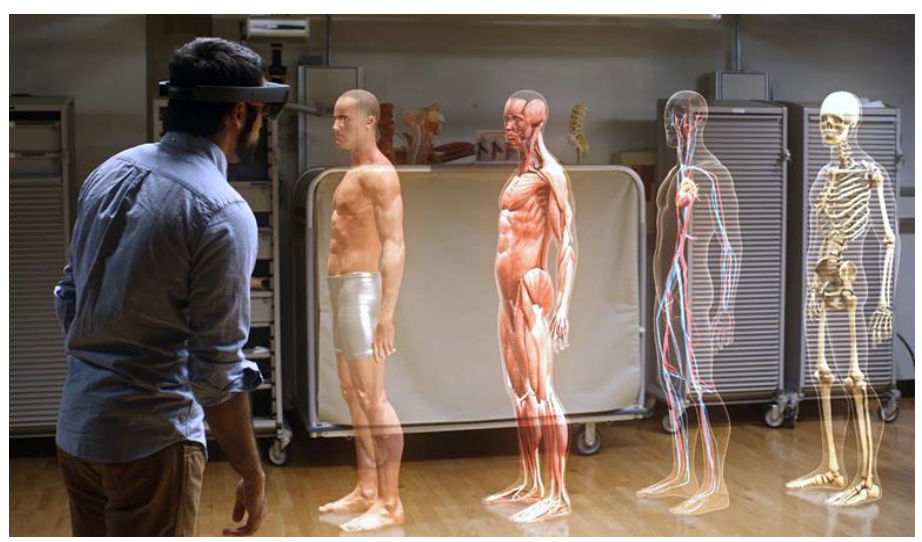

Görsel 6: Karma Gerçeklik ile Anatomi Demosu (HASPULAT, 2021)

Sağlık alanında HAVELSAN'ın yapmış olduğu bir karma gerçeklik çözümü olan Hapsim (Gerçek Dünya Etkileşimi Olan Haptik Destekli Artırılmış Gerçeklik Ortam Altyapısının Geliştirilmesi) simülatörü ile sanal nesnelerin gerçek ortam üzerinde oluşturulması, yenilikçi ve özgün bir tasarımı olan simülasyon ortamında gerçek nesneleri kullanarak, oluşturulan sanal senaryo ile etkileşime geçilmesi, kullanılacak gerçek nesnelerin herhangi bir yere bağlı olmadan, bağımsız olarak kullanılabileceği bir simülasyon ortamı geliştirilmesi, kullanılacak gerçek araçlar ile sanal senaryoya dahil olarak, gerçekçi kuvvet algısının oluşturulması sağlanabilmektedir.

Doktorlara ve tıp öğrencilerine belirli ameliyatlar, prosedürler ve diseksiyonların nasıl yapıldığı öğretilebilir. Çalışmalar, doktorların ilk birkaç düzine cerrahi prosedürü sırasında hata yapma olasılığının daha yüksek olduğunu göstermektedir. $\mathrm{Bu}$ nedenle özellikle karmaşık cerrahi prosedürlerin prova edilmesi karma gerçeklik ile mümkündür. Cerrahi prosedürlerin hızını ve doğruluğunu artırır. Hasta travmasını ve riskini azaltır. Cerrahi işlemler sırasında cerrahlara yardımcı olur. $\mathrm{Bu}$ simülasyonların ve anatominin rahatlıkla anlaşılması dışında hastaların tam olarak vücutlarında olanı görmeleri güvenilirliği arttırır. Sağlık alanı için yeni bir çă̆ başlatan bu teknolojiyi gelecekte hemen her hastanede ihtiyaç olarak göreceğimizi öngörmekteyiz.

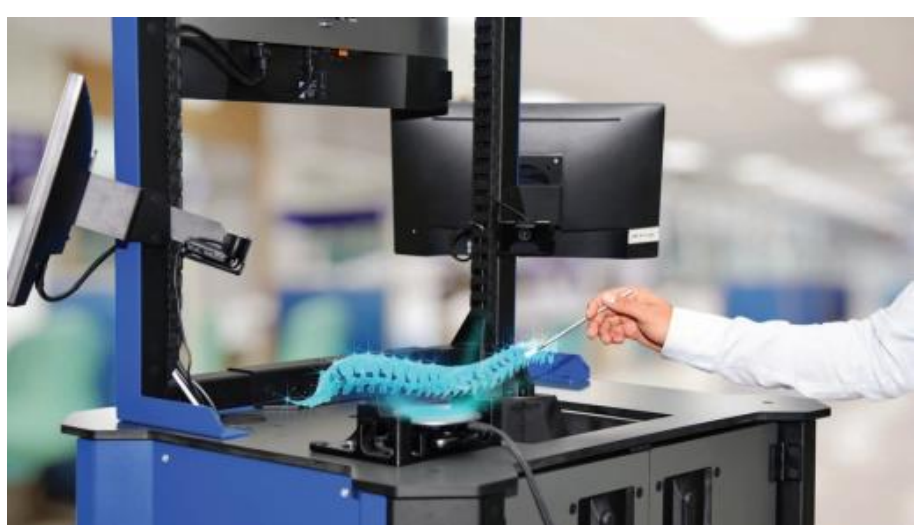

Görsel 7: HAVELSAN Hapsim 


\section{Tartışma ve Öneriler}

Karma gerçeklik teknolojisi, tıbbi alana metin tabanlı fizyolojik verilerin ve çeşitli grafiksel $3 \mathrm{~B}$ verilerin hastanın vücudunda kesintisiz görselleştirilmesi olanağını vermektedir. Böylece hastaların teşhis ve tedavi süreçlerinde iyileştirmeler sağlamaktadır. Hasta bazında bakıldığında bu teknoloji, teşhis, tedavi ve rehabilitasyon süreçlerinin iyileştirilmesine fayda sağlamaktadır. Gelecekte gerçekleşmesi mümkün olan dijital hasta altyapısıyla birlikte karma gerçeklik teknolojisinin kullanımıyla hastaların organları detaylı olarak görülüp yapay zekâ yardımıyla en doğru teşhisin koyulması ve tedavi süreçlerinin efektif bir şekilde sürdürülmesi beklenmektedir. Bunun yanı sira nesil yazıcılarla organ üretilmesiyle de nakil yapan doktorların başarısızlık oranını azaltılabilecektir.

Teknolojinin hekimden, tıp öğrencisine ve hastalara kadar sağlık sektörünü etkileyen tüm fonksiyonlarda uygulanması mümkündür. Bununla birlikte, tıp uzmanlarının çalışmalarının kalitesi, teknolojinin hem kullanışlılığından hem de kullanılabilirliğinden önemli ölçüde etkilenmektedir. Teknoloji, dünyanın ihtiyaçlarına uyacak şekilde gelişerek ilerlemektedir. Gelecekte, sanal gerçeklik başlıkların, artırılmış gerçeklik gözlüklerin ve akıllı dijital cihazların hepsinin karma gerçeklik teknolojili giyilebilir cihazlarda birleşmesi öngörülmektedir. Genişletilmiş gerçeklik ile teknolojilerin bir araya gelmesi aslında düşündüğümüzden çok daha erken gerçekleşebilir. Böylece karma gerçeklik teknolojisinin dünyanın en yaygın ve güçlü bilgi işlem platformlarından biri olacağı düşünülmektedir. Bu yüzden bilim insanları karma gerçekliğin benimsenmesi için gerekli teknolojileri araştırmaya ve geliştirmeye yoğunlaşmış durumdadir.

İlerleyen teknolojiyle birlikte cihazların daha yüksek donanımlara sahip olması ve daha az maliyetle edinilebilmesi sonucunda teknolojinin gelişmesi ve yaygınlaşması beklenmektedir. Yüksek kalitede gerçeklik deneyimi sunan bu teknoloji tıp eğitimindeki birçok ezberi bozacak şekilde, uygulama esaslarında değişime sebep olabilir. Sanal ve gerçek dünyanın nesnelerini bir araya getiren karma gerçeklik teknolojisiyle gözlüklerden sonra kontak lenslerle de bu teknolojinin kullanılabilmesi öngörülmektedir. Yüksek hızda internet alt yapısı ve $5 \mathrm{G}$ gibi teknolojilerin ilerlemesiyle birlikte teletıp alanında birden çok doktor ortak bir vaka üzerinde konsültasyon yapabilmekle birlikte farklı yerlerdeki ameliyatların izlenmesi değerlendirip gerekli durumlarda iletişime geçerek bir manada sanal olarak ameliyata katılıp, ilgili durum için aksiyon alınabilecek bir ortam oluşturulabilecektir. Böylece birçok süreç yer, zaman ve kişiden bağımsız olarak sürdürülebilecek şekilde bir esnekliğe sahip olacaktır.

Sağlık alanındaki gelişmeler hakkında alan uzmanları çeşitli öneri ve öngörülerde bulunmaktadır. Medivis'in karma gerçeklik çözümlerini yorumlayan radyoloji uzmanı Chris Morley teknolojinin kullanımıyla bakım sırasında hasta verilerinin holografik olarak yerleştirilmesinin prosedür sürelerini, komplikasyon oranlarını ve radyasyon maruziyetini azaltabileceğini belirtmiştir. Marienkrankenhaus Hamburg'da kulak, burun, boğaz cerrahı olan Dr. Hans-Jürgen von Lücken hastalara prosedürleri açıklarken karma gerçekliğin kendileri için çok büyük bir avantaj oluğunu açıklayarak bunun sebebinin de hastaların endişelerini daha iyi çözmek için etkileşimli 3B görüntülerle her şeyi açıklayabildiklerini vurgulayarak sağlık personelinin yanı sıra hastalar içinde teknolojinin önemine vurgu yapmıştır (Microsoft, 2021). Sağlık alanında karma gerçeklik teknolojinin kullanımı ve uygulama alanlarının çeşitlenerek artması beklenmektedir.

Karma gerçeklik sadece sağlık ve eğitim alanlarında da değil aynı zamanda askeri, otomotiv ve iş dünyasında da kullanım örneklerinin yaygınlaşacağ 1 bir teknoloji haline gelmektedir. Karma gerçeklik sayesinde dar alanlarda bile, örneğin otomobil gibi çeşitli ürünlerin karma gerçeklikle sunulduğu ve satışının gerçekleştirilmesi mümkündür. Böylece galerilere otomobilleri sığdırmak yerine karma gerçeklik teknolojisinin sunmuş olduğu imkânlardan faydalanılabilecektir. Birçok sektör bu şekilde çevrimiçi mağazalar açarak müşteri ve kullanıcılarına bireysel ürün deneyimi sunabileceklerdir.

\section{Sonuç}

Sanal ve gerçek dünyanın buluşturan karma gerçeklik teknolojisi özellikle eğitim ve sağlık alanında aktif gelişimini sürdürerek sağlık alanındaki uygulamalarla kendini duyurmasına rağmen askeri, otomotiv, pazarlama vb. gibi birçok alanda kullanıma uygun bir teknolojidir. Fakat şuana kadar sağlık alanındaki çalışmalarla kendinden oldukça söz ettirmiş olan bu teknoloji tıp eğitiminden, hastalıkların teşhis ve tedavi süreçlerine kadar pek çok alanda farklı uygulama örneklerini görmek mümkündür. Hızlı bir ivme ile gelişmeye ve ilerlemeye devam eden karma gerçeklik gibi görüntüleme teknolojileri birçok konuda zaman, mekân ve kişilerden bağımsız olarak ilgili süreçlerin işletilebilmesi veya uzaktan da verimli bir şekilde yürütmeyi temel almaktadır. Geçmişte sadece hayal edilebilen sanal dünyalar oluşturma, sanal ve gerçek dünyanın örtüştürülebilmesi artık artırılmış, sanal ve karma gerçeklikle mümkün hale gelmiştir. Yapılan bu çalışmada karma gerçekliğin sunduğu imkânlardan maksimum fayda sağlayabilecek uygulamalı bir alan olan sağlık alanındaki çalışmaları yapılan uygulamaları inceledik. Yakın gelecekte de özellikle tıp eğitiminde, hastalıkların teşhis ve tedavisine yönelik kullanımların yaygınlaşacaktır. Simülasyon teknolojilerinde bir dünya markası haline gelen, yazılım ağırlıklı özgün çözüm ve ürünlere sahip olan HAVELSAN, alanında ulusal ve uluslararası lider sistem entegratörü olma vizyonuyla hareket etmekte, gelişen teknolojilerden maksimum faydayı sağlayacak bir yaklaşım izlemektedir. Bu kapsamda yeni nesil teknolojiler üzerinde aktif çalışmalarımızı sürdürmekteyiz. Simülasyon teknolojisinin ana faaliyet alanımız olması ve çok çeşitli disiplinleri içermesi nedeniyle HAVELSAN olarak, yeni nesil teknolojilerden biri olan karma gerçeklik teknolojisini temel alan Hapsim simülatörünü gerçekleştirdik. Bunun gibi, karma gerçeklik alandaki gelişmeleri takip ederek farklı çözümler geliştirmeye devam ediyoruz. Gelecek çalışmalarımızda sağlık alanının yanı sıra askeri alanda da karma gerçeklik teknolojisine yönelik çalışmalar gerçekleştirmeyi planlamaktayız.

\section{Kaynakça}

apoQlar. (2020). Experience Collaborative Medicine - VSI HoloMedicine $\AA$. https://apoqlar.com/

Case Western Reverse University. (2016). CWRU, Cleveland Clinic release first third-party app for Microsoft HoloLens.

Groves, M. (2019). Philips and Microsoft HoloLens 2: augmented for image guided therapy - News | Philips. https://www.philips.com/aw/about/news/archive/standard/news/articles/2019/2019031 
3-philips-and-microsoft-hololens-2-could-augmentedreality-change-the-face-of-image-guided-therapy.html

HASPULAT, M. (2021). Tıp Eğitiminde Yeni Yaklaşımlar; AR, XR, MR - IVEK Akademi. https://ivekakademi.org/blog/tipegitiminde-yeni-yaklasimlar-ar-xr-mr/

HoloNext. (2020). Artırılmış Gerçeklik Uygulamaları ve AR Teknolojisinin Geleceği - Holonext. https://holonext.com/tr/artirilimis-gerceklik-uygulamalari/

Intel. (2020). Sanal Gerçeklik ve Artırılmış Gerçeklik ve Karma Gerçeklik Intel. https://www.intel.com.tr/content/www/tr/tr/tech-tips-andtricks/virtual-reality-vs-augmented-reality.html

Mcgurk, M. (2021). CASE DESCRIPTION HOLOMEDICINE How a nerve was saved with VSI Holomedicine. www.vsi.health

Microsoft. (2021). Microsoft Karma Gerçeklik - Sağlık Hizmetleri. $\quad$ https://www.microsoft.com/trtr/hololens/industry-healthcare

Park, M.-C., Lee, H.-D., \& Son, J.-Y. (2012). 3D display simulator based on mixed reality. Https://Doi.Org/10.1117/12.921448, 8384, 249-254. https://doi.org/10.1117/12.921448

Steiger, A. (2020). HoloLens 2 vs Magic Leap Features: Battle of XR Headsets.

Verhey, J. T., Haglin, J. M., Verhey, E. M., \& Hartigan, D. E. (2020). Virtual, augmented, and mixed reality applications in orthopedic surgery. The International Journal of Medical Robotics and Computer Assisted Surgery, 16(2), e2067. https://doi.org/10.1002/RCS.2067 